\title{
Pseudomembrane Formation
}

National Cancer Institute

\section{Source}

National Cancer Institute. Pseudomembrane Formation. NCI Thesaurus. Code C67353.

Formation of membrane-like structures consisting of coagulated exudate that is loosely adherent to an inflamed tissue. 